Goldschmidt 2021 Abstract

https://doi.org/10.7185/gold2021.4642

\section{An improved thermodynamic model based on Pitzer's equations to describe the chemical behaviour of complex chloride-type brines up to salt solubility and elevated temperatures, for geothermal and economic geology applications}

\author{
ARNAULT LASSIN ${ }^{1}$, MATHIEU DEBURE ${ }^{2}$, JOHANN \\ TUDURI $^{1,3}$ AND LAURENT ANDRE ${ }^{1,4}$ \\ ${ }^{1} \mathrm{BRGM}$ \\ ${ }^{2}$ BRGM - THE FRENCH GEOLOGICAL SURVEY \\ ${ }^{3}$ Institut des Sciences de la Terre d'Orléans \\ ${ }^{4}$ ISTO \\ Presenting Author: a.lassin@brgm.fr
}

The context of global warming has changed our perception of the Earth's subsurface, which is now seen as a source of renewable energy and of valuable elements contained in geothermal waters, as well as a vast geological reservoir for storing energy vectors or gases. Therefore, the description of the chemical processes occurring in deep and hot geological environments has recently gained renewed interest and contributes to the understanding of geological phenomena, including ore forming processes and the set-up of dehydrate formation layers ${ }^{1}$.

Deep waters are most often salty and hot, which makes the description of their chemical behaviour a challenge. The present contribution focuses on developing a new thermodynamic model for the $\mathrm{H}-\mathrm{Li}-\mathrm{Na}-\mathrm{K}-\mathrm{Ca}-\mathrm{Mg}-\mathrm{Cl}-\mathrm{H}_{2} \mathrm{O}$ chemical system, from dilute solutions up to salt solubility, and for temperatures up to $250^{\circ} \mathrm{C}$. This model relies on the Helgeson-Kirkham-Flowers (HKF) and the Pitzer equations, and considers the partial dissociation of the $\mathrm{CaCl}_{2}$ electrolyte. It has been implemented in the PhreeSCALE ${ }^{2}$ geochemical calculation software to compute properties such as osmotic coefficient (Figure), heat capacity, enthalpy and density of chloride-bearing multi-electrolyte solutions in conditions relevant for the production of geothermal energy.

The model is also able to predict the formation of highly soluble salts like tachyhydrite $\left[\mathrm{CaCl}_{2} \cdot 2 \mathrm{MgCl}_{2} \cdot 12 \mathrm{H}_{2} \mathrm{O}\right]$, observed in giant salts deposits, below the deep ocean's crust, in the passive margin of the Atlantic Ocean. Recent works suggest that the formation of such salts may be related to the serpentinization process of the primary mantle peridotite that consumes important amounts of pore water and leads to extremely concentrated brines in hot environments.

These encouraging results suggest that the model should be further extended and used for other applications, like the transport of dissolved metals from deep hot fluids to areas where metals in solution will be extracted from these fluids, and concentrated to make ore bodies.

This study was done in the framework of the REFLECT Project, funded by the European Union's Horizon 2020 research and innovation programme (grant agreement No 850626).

\section{References}

[1] Debure et al. (2019). Sci. Reports, 9, 11720. https://doi.org/10.1038/s41598-019-48138-9

[2] Lach et al. (2016). Comput. Geosci, 92, 58-69. https://doi.org/10.1016/j.cageo.2016.03.016

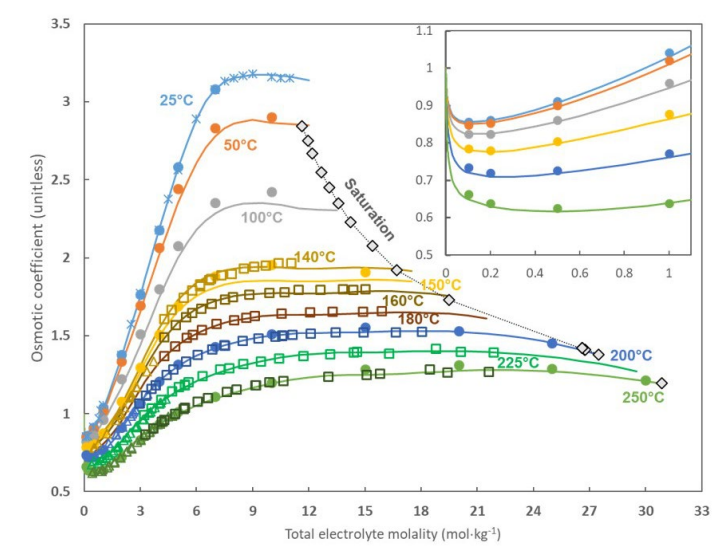

Osmotic coefficient of $\mathrm{CaCl}_{2}$ aqueous solutions as a function of electrolyte concentration over the temperature range $25-250^{\circ} \mathrm{C}$. Symbols represent experimental data; lines represent calculated values (this work). 